
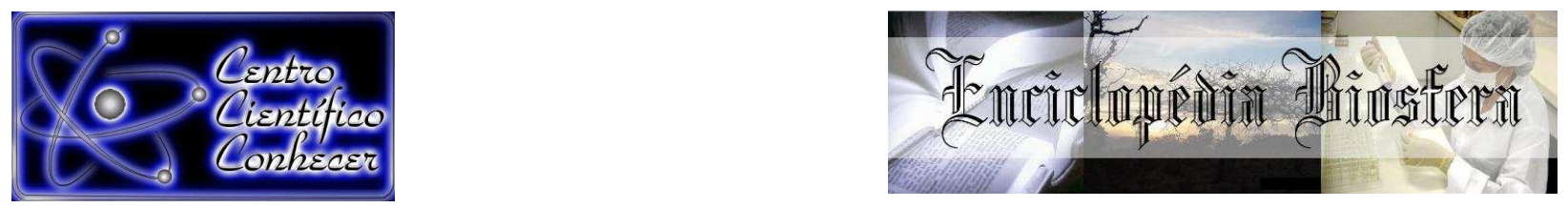

\title{
COMPORTAMENTO DA PRODUÇÃO E DO MERCADO DE PESCADO NO BRASIL E NO ESTADO DO PARÁ
}

\author{
Luciane Marçal Oliveira'; ${ }^{1}$ Luan Freitas Rocha ${ }^{1}$; Sávio Lucas de Matos \\ Guerreiro'; Marcos Antônio Souza dos Santos ${ }^{2}$ \\ ${ }^{1}$ Engenheiros de Pesca formados pela Universidade Federal Rural da \\ Amazônia, Belém/PA - Brasil \\ ${ }^{2}$ Professor Doutor do Instituto Socioambiental e dos Recursos Hídricos da \\ Universidade Federal Rural da Amazônia, Belém/PA - Brasil, \\ (marcos.santos@ufra.edu.br) \\ Recebido em: 02/10/2017 - Aprovado em: 21/11/2017 - Publicado em: 05/12/2017 \\ DOI: 10.18677/EnciBio_2017B16
}

RESUMO

Este artigo avaliou o comportamento do mercado mundial, nacional e da região Norte do Brasil, quanto à evolução da produção, consumo e balança comercial de pescados. Foram utilizados dados oficiais da Organização das Nações Unidade para Alimentação e Agricultura (FAO), Instituto Brasileiro de Geografia e Estatística (IBGE), Ministério da Pesca e Aquicultura (MPA) e Ministério do Desenvolvimento, Indústria e Comércio Exterior (MDIC). Os dados foram submetidos à análise descritiva para elaboração tabelas, gráficos e mapas. Os resultados indicam que a produção mundial e nacional de pescado tem crescido nas últimas décadas em função do desenvolvimento da aquicultura. A produção nacional apresenta pouca inserção no mercado internacional, pois é pequena quando comparada a outros países. As principais regiões produtoras de pescado são a Nordeste, Norte e o Sul, onde Santa Catarina é o estado de maior destaque, com o estado do Pará ocupando o segundo lugar. O Brasil e o estado do Pará apresentam excelente potencial para a expansão da aquicultura e o desenvolvimento dessa atividade é fundamental para ampliar a oferta de pescado, atender o crescimento do mercado consumidor e contribuir com a sustentabilidade da pesca extrativa, a partir da redução da pressão sobre os estoques pesqueiros de águas marinhas e continentais.

PALAVRAS-CHAVE: Amazônia Brasileira, Análise de Mercado, Economia Pesqueira.

\section{BEHAVIOR OF FISH PRODUCTION AND MARKET IN BRAZIL AND THE STATE OF PARÁ}

\footnotetext{
ABSTRACT

The article evaluates the behavior of the world market, national and the northern region of Brazil, regarding the evolution of production, consumption and trade balance of fish. Official data from the United Nations Organization for Food and Agriculture (FAO), the Brazilian Institute of Geography and Statistics (IBGE), the Ministry of Fisheries and Aquaculture (MPA) and the Ministry of Development, Industry and Foreign Trade ENCICLOPÉDIA BIOSFERA, Centro Científico Conhecer - Goiânia, v.14 n.26; p. 181 2017
} 
(MDIC) were used. The data were submitted to descriptive analysis to elaborate tables, graphs and maps. The results indicate that world and national production of fish has grown in the last decades due to the development of aquaculture. The national production shows little insertion in the international market, because it is small when compared to other countries. The main fish producing regions are the Northeast, North and South, where Santa Catarina is the most prominent state, with the state of Pará occupying second place. Brazil and the state of Pará have excellent potential for the expansion of aquaculture and the development of this activity is fundamental to expand the supply of fish, to meet the growth of the consumer market and to contribute to the sustainability of extractive fishing, by reducing pressure on fish stocks of marine and continental waters.

KEYWORDS: Brazilian Amazon, Fisheries economics, Market analysis.

\section{INTRODUÇÃO}

A captura por pesca e a aquicultura fornecem anualmente cerca de 154 milhões de toneladas de pescado, sendo 115 milhões destinados ao consumo humano, proporcionando uma disponibilidade per capita de aproximadamente 17 $\mathrm{kg} / \mathrm{hab}$./ano o que ressalta a importância do pescado para a economia e a segurança alimentar (FAO, 2010). Diante desse contexto, a aquicultura assim como a pesca artesanal e industrial possuem uma ampla contribuição no processo de desenvolvimento econômico e de combate à pobreza em todo o mundo (FAO, 2010).

O Brasil não é um grande exportador de pescado, pois sua produção é pequena comparativamente e de outros países. Entretanto, a produção nacional de pescado desempenha uma importante função socioeconômica, pois compõe a dieta alimentar de milhões de habitantes, além dos importantes efeitos na estrutura econômica do país por meio da geração de renda e ocupações de mão de obra (LOPES et al., 2010).

A produção nacional de pescado concentra-se nas regiões Nordeste e Sul, sendo Santa Catarina o estado maior produtor do país. O estado do Pará ocupa o segundo lugar e o primeiro na Amazônia Brasileira, região em que a pesca é uma atividade tradicional e que fornece alimento essencial para populações rurais a urbanas (BRASIL, 2011).

O litoral Amazônico se estende por mais de $1.500 \mathrm{~km}$ de extensão, incluindo os estados do Pará, Amapá e Maranhão (SUGUIO; TESSLER, 1984). Esta região caracteriza-se em possuir condições favoráveis para produção de recursos pesqueiros, pois é rica em matéria orgânica proveniente da decomposição das florestas de mangue e das planícies inundadas do Rio Amazonas, além disso, a ação de rios que carregam sedimentos para plataforma continental, sendo assim, todos esses fatores contribuem para que a área possua uma vocação natural para exploração dos recursos pesqueiros (ISAAC, 2006). A atividade pesqueira no litoral Norte do país é realizada tanto dentro dos estuários como na região costeira, até os limites da plataforma continental (ISAAC et al., 2006).

Pela relevância da produção e do mercado pesqueiro para o Brasil e, especialmente, para o estado do Pará, neste artigo apresenta-se uma análise do comportamento do mercado mundial, nacional e regional de pescado, abrangendo o período 1990 a 2015. 


\section{MATERIAL E MÉTODOS}

Foram utilizados dados secundários obtidos nas seguintes fontes: Food and Agriculture Organization (FAO); Sistema de Análise das Informações de Comércio Exterior via Internet do Ministério do Desenvolvimento, Indústria e Comércio Exterior (Sistema ALICEWEB); Ministério da Pesca e Aquicultura do Brasil (MPA); Instituto Brasileiro de Geografia e Estatística (IBGE). Os dados foram analisados estatisticamente no Microsoft Excel versão 2013 empregado na elaboração de gráficos e tabelas.

\section{RESULTADOS E DISCUSSÃO}

\section{Mercado internacional}

Os dados da Organização das Nações Unidas para a Agricultura e Alimentação (FAO, 2014) indicam que, em 2011, a produção mundial de pescado foi de aproximadamente 154 milhões de toneladas, onde a pesca extrativa contribui com 90,4 milhões e a aquicultura com 63,6 milhões. Entre 2002 a 2011 a produção cresceu cerca de $1,43 \%$ ao ano. Embora a maior parcela dessa produção seja proveniente da pesca, o responsável pelo crescimento foi a aquicultura que cresceu $4,64 \%$ ao ano, enquanto a oferta da pesca extrativa decresceu $0,3 \%$ ao ano nesse período.

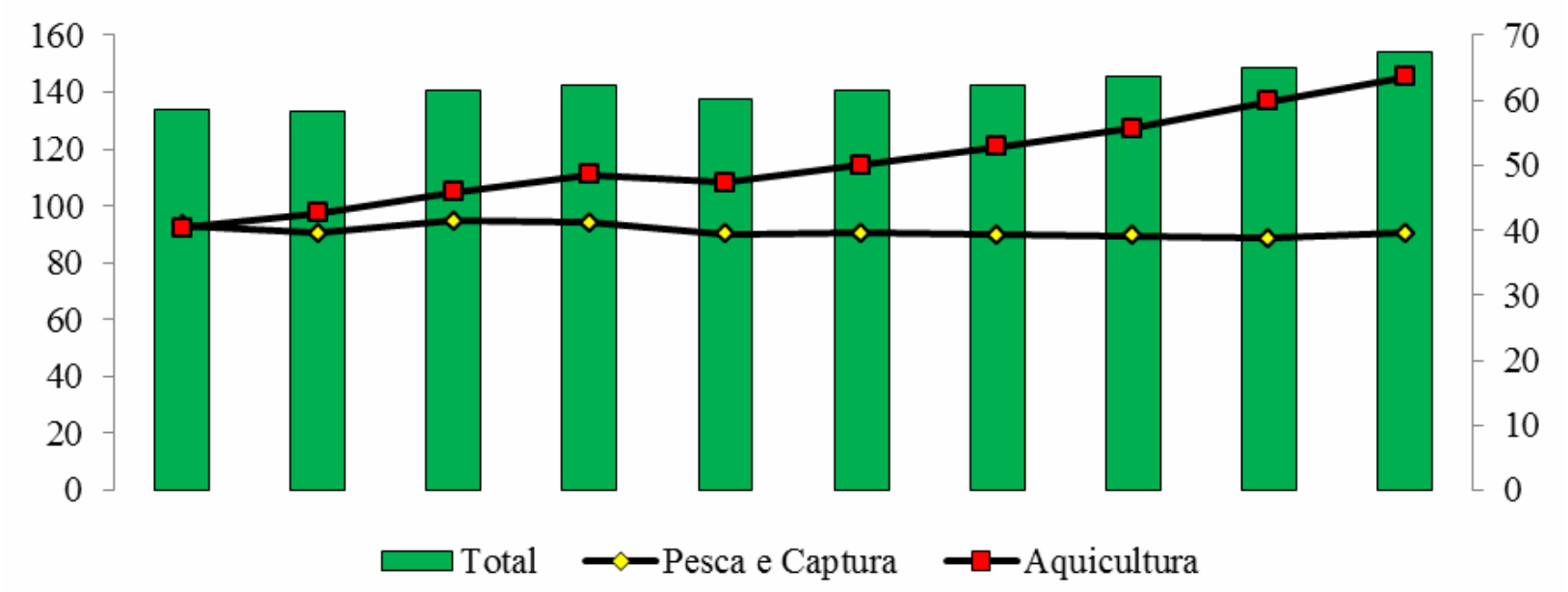

FIGURA 1. Produção de pescado (Pesca e Aquicultura) de 2002-2011 em milhões de toneladas.

Fonte: FAO (2014).

Quando se analisa a produção pesqueira de áreas continentais nota-se o domínio do continente asiático, principalmente, na aquicultura com representatividade de $89 \%$, já na pesca o continente responde por $50 \%$ da produção mundial (Figura 2). 

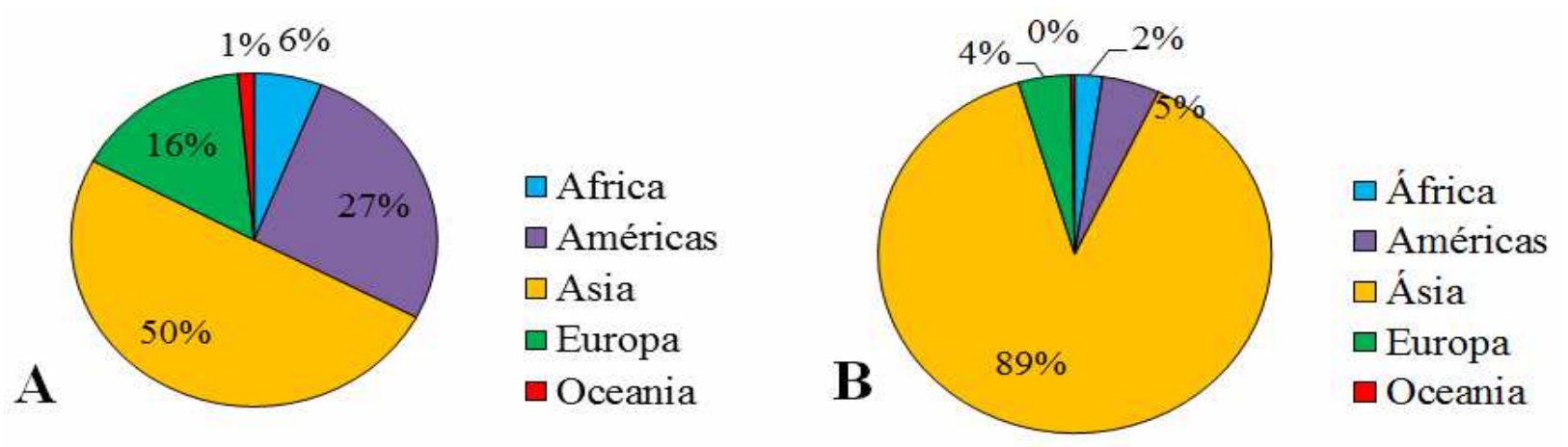

FIGURA 2. Produção de pescado por continente no ano de 2011. A) Pesca e B) Fonte: FAO (2014). Aquicultura.

Pode-se compreender melhor a representatividade asiática, quando observa-se os 10 principais países produtores de pescado no ano de 2011. A China liderou a produção, posição que encontra-se desde o ano de 1998 (LOPES et al., 2010). Também nota-se que em países como China e Vietnã a produção aquícola já superou a pesca extrativa, no entanto em países como Índia, Indonésia, Chile e Myanmar a produção da pesca ainda é superior (Tabela 1).

TABELA 1. Os 10 principais países produtores de pescado no mundo em 2011.

\begin{tabular}{l|c|l|c}
\hline \multicolumn{3}{c}{ Aquicultura (Milhões de t) } & Pesca (Milhões de t) \\
\hline China & 38,6 & China & 15,8 \\
Índia & 3,7 & Peru & 8,2 \\
Vietnã & 2,8 & Indonésia & 5,8 \\
Indonésia & 2,7 & USA & 5,2 \\
Bangladesh & 1,5 & Índia & 4,3 \\
Noruega & 1,1 & Rússia & 4,3 \\
Tailândia & 1,2 & Japão & 3,8 \\
Chile & 1,1 & Myanmar & 3,3 \\
Egito & 1,0 & Chile & 3,1 \\
Myanmar & 0,9 & Vietnã & 2,5 \\
Fonte: FAO (2014).
\end{tabular}

Fonte: FAO (2014).

Quanto ao consumo total, em 2010, $87,6 \%$ (130,1 milhões de toneladas) do pescado capturado foram destinados à alimentação humana, onde o continente asiático foi responsável por ofertar cerca de $69 \%$ (89,8 milhões de toneladas). Com relação consumo per capita, o continente asiático é apenas o quarto maior com 21,6 $\mathrm{kg} / \mathrm{hab}$./ano, ficando atrás da Oceania (25,4 kg/hab./ano), Europa (22 kg/hab./ano) e América do Norte $(21,8 \mathrm{~kg} / \mathrm{hab}$./ano). A África e a América do Sul possuem consumo bem inferior com média de $9,7 \mathrm{~kg} / \mathrm{hab}$./ano, valores que de acordo com Lopes et al. (2010), os caracterizam como países em desenvolvimento, pois consomem menos de $15 \mathrm{~kg} / \mathrm{hab}$./ano (Figura 3). 


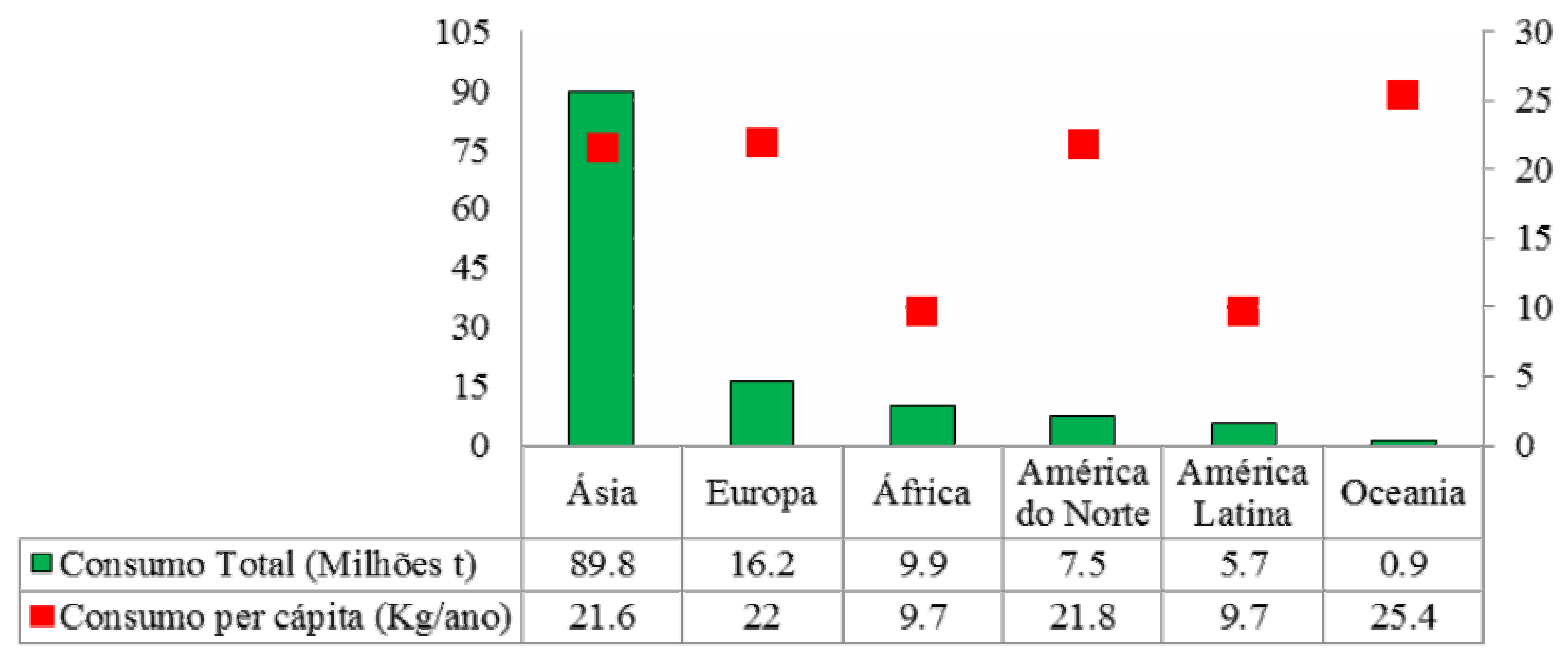

FIGURA 3. Pescado destinado ao consumo e consumo per capita, 2010.

Fonte: FAO (2014).

No ano de 2012 as exportações de pescado movimentaram US $\$ 129,2$ bilhões o que, comparado com 2011 representou redução de 0,46\%. Quando trata-se dos 10 principais exportadores, a China lidera o ranking sendo responsável por $14 \%$ do valor total mundial (Figura 4).

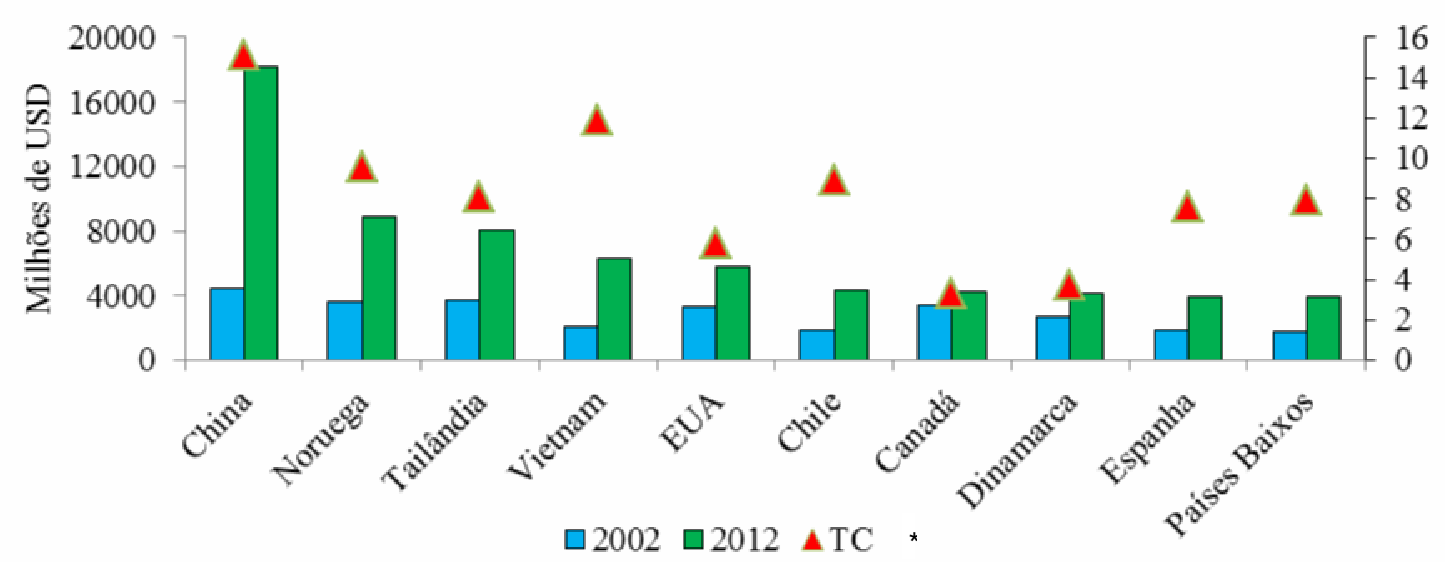

FIGURA 4. Os 10 principais países exportadores de pescado no ano de 2012.

Fonte: FAO (2014). Nota: ${ }^{*}$ TC: Taxa de crescimento

Observa-se que a partir de 2002, as exportações de pescado chinesas têm crescido significativamente, sendo observada uma taxa média de $15,1 \%$ ao ano, entre os anos de 2002-2012. Este desempenho possibilitou à China ocupar o primeiro lugar em termos de quantidade e valor das exportações, o que se deve ao desenvolvimento da indústria pesqueira e à disponibilidade de mão de obra barata, além de baixos custos de produção (FAO, 2014).

Segundo a FAO (2014), além de exportar a própria produção, a China também processa e exporta pescado importado, por isso ocupa o terceiro lugar como importador mundial de pescado. Ao longo da última década, o desenvolvimento desta atividade favoreceu o aumento substancial das importações, crescendo em torno de 13\% de 2002 a 2012, ficando atrás apenas do Japão e dos Estados Unidos (Figura 5). 


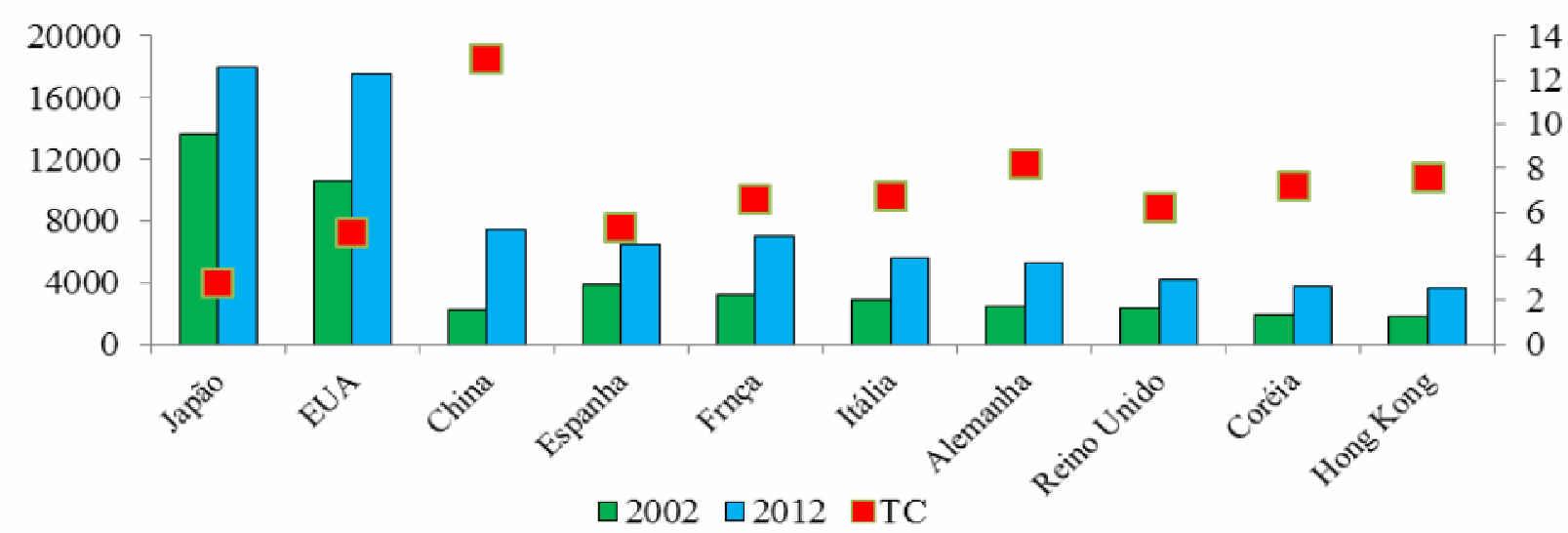

FIGURA 5. Os 10 principais países importadores de pescado no ano de 2012.

Fonte: FAO (2014). Nota: * TC: Taxa de crescimento

Em 2012, as importações mundiais atingiram US\$129,4 bilhões. Pode-se notar na Figura 5 que o Japão é o principal importador, seguido pelos Estados Unidos e juntos representam $27,5 \%$ do valor das importações mundiais. Segundo a FAO (2014), nos Estados Unidos e no Japão o pescado proveniente da importação representa, respectivamente, $60 \%$ e $54 \%$ do consumo total do país. Também é notável a participação de países da União Europeia como Espanha, França, Itália, Alemanha e Reino Unido que juntos representaram $22 \%$ do valor das importações mundiais.

\section{Mercado nacional}

De acordo com o Ministério da Pesca e Aquicultura (BRASIL, 2010) a produção nacional de pescado, no período de 1950 a 2010, foi marcada por comportamentos distintos em diversos subperíodos. Entre 1950 e 1985, ocorreu expansão acentuada da captura, fase em que foi registrado o maior volume de produção (956.684 t). Os fatores determinantes desse aumento foram: o Programa de industrialização da pesca, implantado pelo Governo Juscelino Kubitschek, na década de 1950; Criação, em 1962, da Superintendência de Desenvolvimento da Pesca (SUDEPE) e a publicação do Decreto-Lei 221, de 28/02/1967, que estabeleceu o novo Código de Pesca.

Entre 1986 e 1990 ocorreu decréscimo gradativo das capturas, quando a produção declinou de 946.560 t para 619.805 t, configurando o início da sobrepesca de diversos estoques, tais como: a sardinha-verdadeira, camarões e peixes demersais do Sul do Brasil. Adicionalmente, em meados da década de 1980, os incentivos fiscais cessaram, reforçando o declínio da produção pesqueira nessa fase. De 1990 até o ano 2000, a produção ficou estável (BRASIL, 2010). Em 1990, por exemplo, esse montante foi de apenas 640,3 mil toneladas (FAO, 2010).

A partir do ano 2000, a produção retomou uma trajetória de crescimento, passando de 666.846 t para 785.366 t, em 2010. Este crescimento ocorreu em função da recuperação de alguns estoques como, por exemplo, o da sardinha verdadeira. Segundo a FAO (2010), o padrão de crescimento tem se mantido, principalmente, pela contribuição da aquicultura que, no período de 1996/2010, cresceu a uma taxa média de $12,86 \%$ ao ano, elevando a sua participação de $8,76 \%$, em 1996 , para $37,89 \%$, em 2010, no total de pescado produzido no Brasil (Figura 6). 


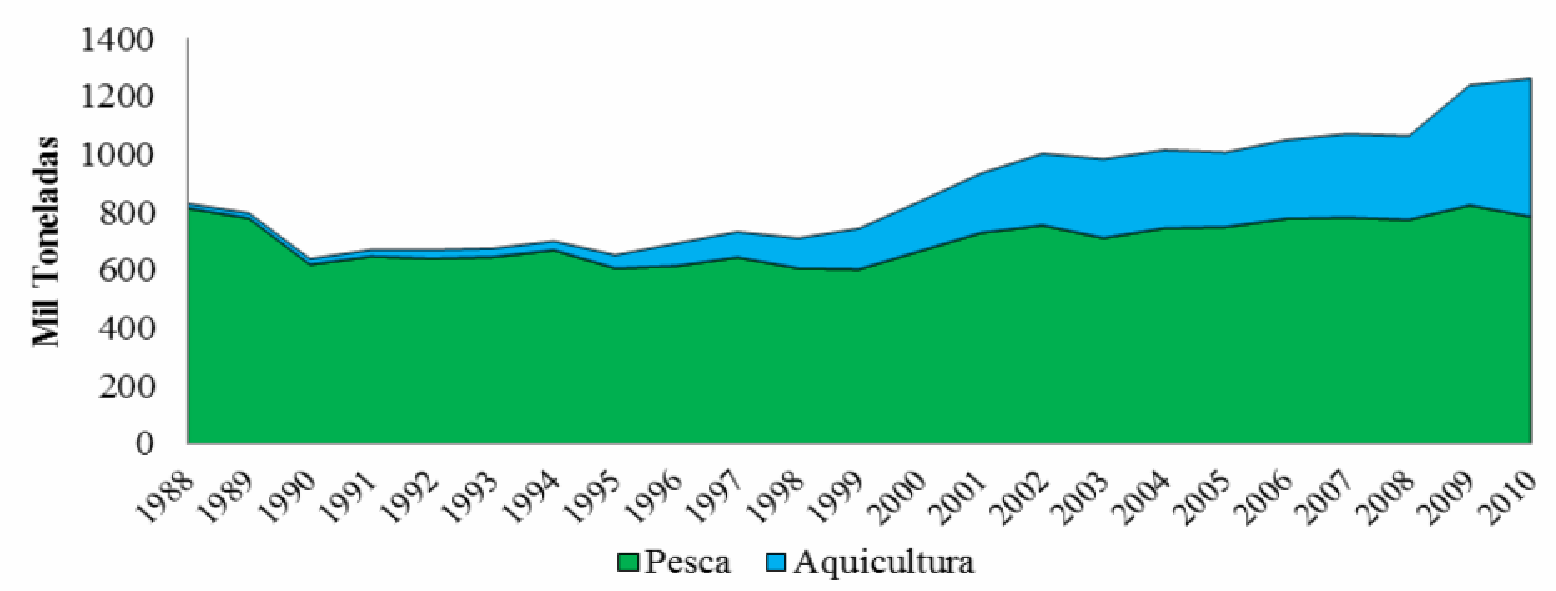

FIGURA 6. Produção da pesca e aquicultura no Brasil ao longo de 1988-2010.

Fonte: FAO (2010).

Segundo levantamento estatístico divulgado pelo Ministério da Pesca e Aquicultura (MPA), em 2010, a aquicultura apresentou significativo crescimento nos últimos anos, passando de 278 mil toneladas, em 2003, para 415 mil toneladas, em 2009. Isso corresponde a um incremento de $35 \%$, em menos de uma década. Em 2011, a produção nacional de pescado foi de $1.431 .974,4 \mathrm{t}$, o que correspondeu a acréscimo de 13,2\% em relação ao ano de 2010 (BRASIL, 2011).

As principais regiões produtoras de pescado nos anos de 2010 e 2011 foram o Nordeste e o Sul. Sendo que o Nordeste contribuiu com 454.217 toneladas e o Sul com 336.451,5 t em 2011. A região Norte apesar de estar abaixo das outras regiões em produção no ano de 2011 contribui significativamente com 326.128,4 t com avanço de $19 \%$ em relação a 2010 que correspondeu a uma produção de 274.015,6 toneladas (Figura 7). Mesmo apresentando uma baixa participação a Região Centro-Oeste também apresenta potencial para a aquicultura, já que há disponibilidade de água, proximidade da agroindústria com a produção de grãos e rações e empresários capitalizados e inúmeros empreendedores dispostos a investir em negócios de grande escala (BRASIL, 2011).

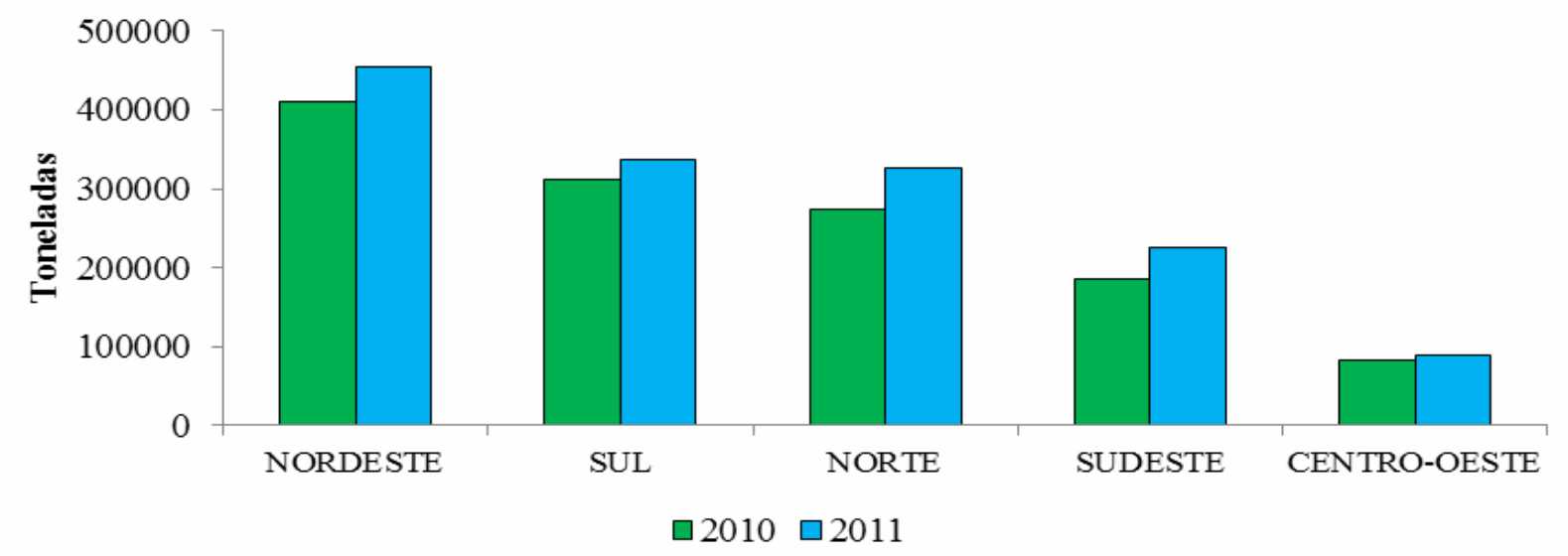

FIGURA 7. Produção nacional de pescado (t), em 2010 e 2011, segundo as grandes regiões do Brasil.

Fonte: BRASIL (2011). 
Em 2011, a distribuição da produção nacional de pescado, segundo as Unidades da Federação, mostrou que Santa Catarina se manteve como maior produtor nacional, com 194.866,6 t (13,6\%), seguido pelo Pará, com 153.332,3 t (10,7\%), e o estado do Maranhão com 102.868,2 t. Os estados da Bahia, Rio Grande do Sul, São Paulo, Mato Grosso, Alagoas, Sergipe e Distrito Federal exibiram redução comparativamente ao total produzido em 2010. Contudo, para os demais estados, constatou-se um incremento na produção de pescado em relação a 2010 (Figura 8).

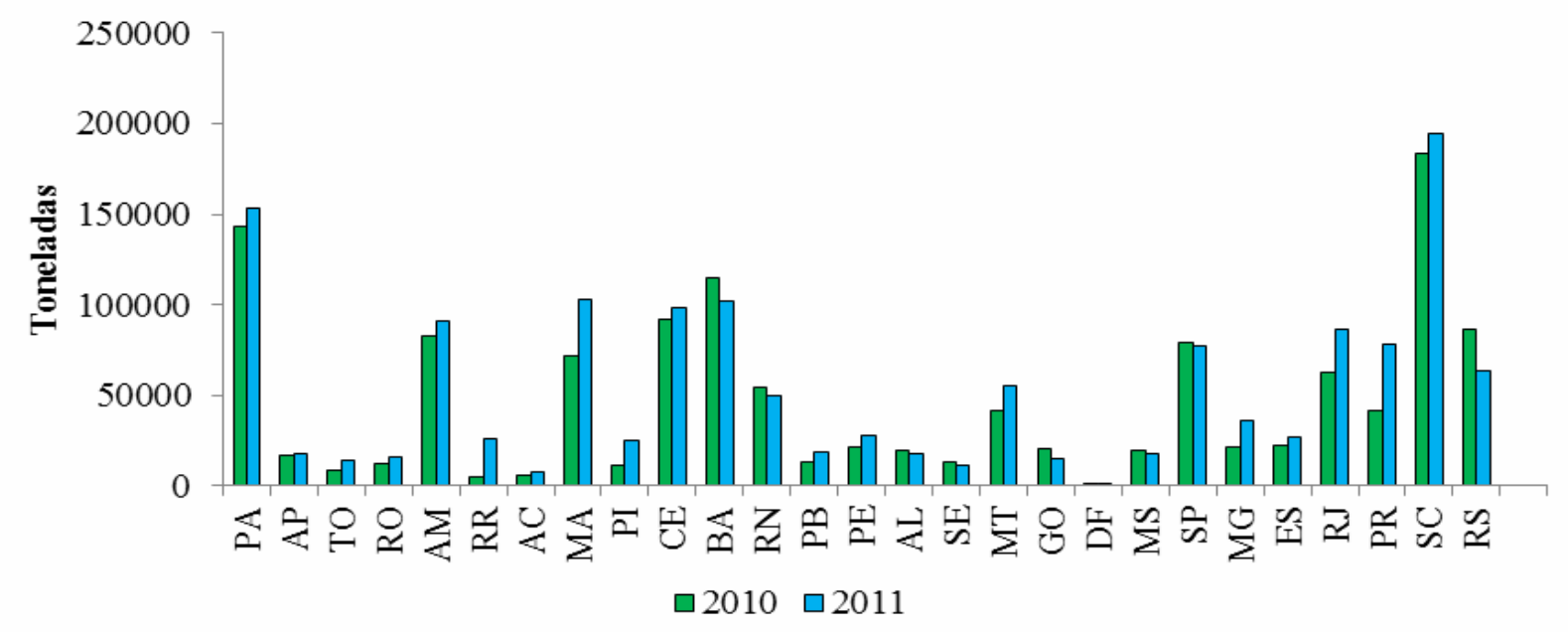

FIGURA 8. Produção nacional de pescado (t), em 2010 e 2011, segundo Unidade da Federação. Fonte: BRASIL (2011).

Segundo a FAO (2010), a participação brasileira no mercado mundial de pescado ainda é tímida. Em 2006, as exportações mundiais de pescado representavam um mercado de US\$ 86 bilhões/ano e o Brasil participava com pouco mais de US\$ 374 milhões (Figura 9).

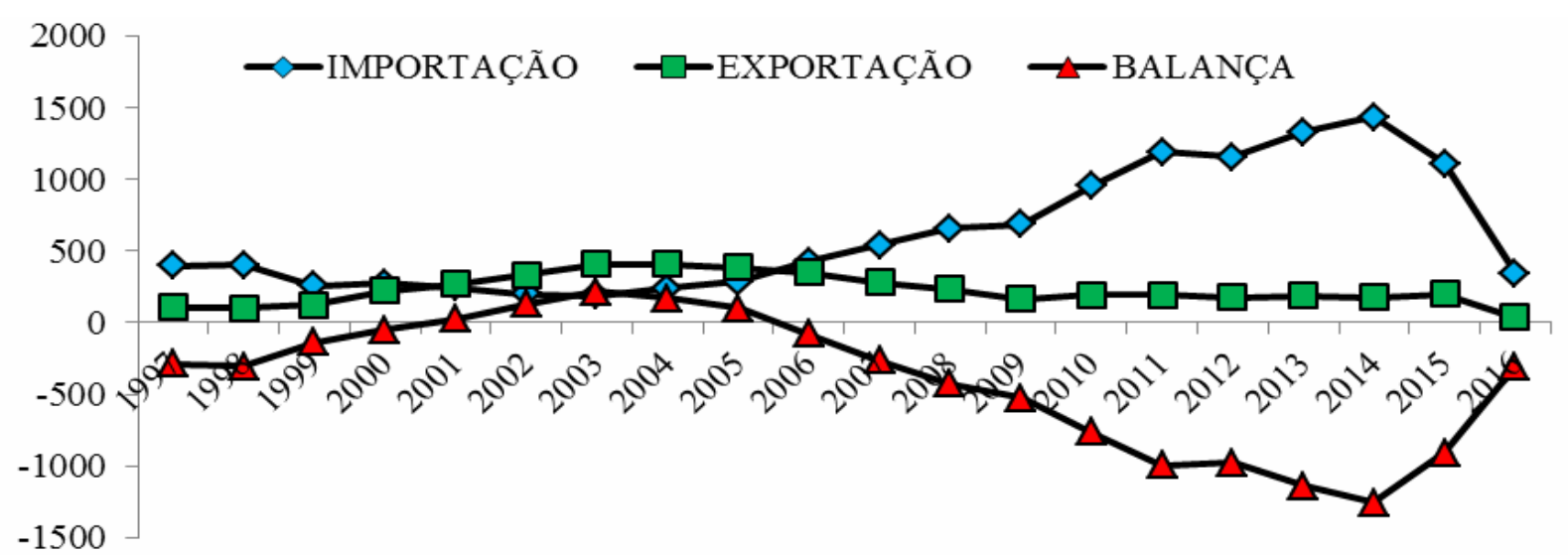

FIGURA 9. Comportamento da balança comercial de pescado no Brasil entre 1997 2016.

Fonte: BRASIL (2016).

A análise dos dados de exportação e importação de pescado no Brasil extraídos do MDIC/AliceWeb, mostra que no período de 1997 a 2005 o valor das exportações mais que triplicou e a quantidade exportada foi ampliada em quatro vezes, ENCICLOPÉDIA BIOSFERA, Centro Científico Conhecer - Goiânia, v.14 n.26; p. 188 2017 
correspondendo a um crescimento de $19,71 \%$ a.a e $22,48 \%$ a.a, respectivamente.

Segundo Lopes et al. (2010), um dos principais fatores desse crescimento está relacionado ao aumento da produção de camarão marinho cultivado, visto que em 2001 representou 45,5\% das exportações pesqueiras do país. Toda via, nota-se que entre 2006 e 2010 o valor das exportações recuou 15,26\% a.a e a quantidade $20,85 \%$ a.a. Dentre os fatores que contribuíram para esse resultado está a queda nas vendas de camarão aos EUA, cujo peso na pauta exportadora brasileira sempre foi significativo, passando de 59\% do montante vendido, em 2003, para 17\%, em 2009. Desde 2010 até a atualidade é possível observar que as exportações de pescado brasileiro têm mantido um comportamento estável e sem tendência de crescimento.

Quanto às importações observou-se um comportamento contrário. Entre 1997 e 2005 houve um recuo no valor e na quantidade de 6,81\% e 4,56\% a.a, respectivamente. Considerando o período de 2006 a 2010, nota-se uma recuperação no valor de 20,31\% e 10,52\%a.a na quantidade (LOPES et al., 2010). No que se refere às importações brasileiras de Pescado no ano de 2014, é possível observar que houve um incremento de $7,5 \%$ em valor, no acumulado de janeiro a março de 2014 , quando comparado com o mesmo período de 2013, chegando à casa de US\$ 500 milhões no primeiro trimestre deste ano. (ABCC, 2014).

O saldo da balança comercial brasileira de produtos pesqueiros passou por três fases distintas, entre 1996 e 2016. Na década de 1990 ocorreram contínuos déficits, contudo entre os anos de 2001 e 2005 observaram-se superávits. Porém, a partir de 2003 até meados de 2014 passou a ocorrer um acréscimo nas importações, e estabilização seguida de queda, nas exportações, o que deflagrou uma nova tendência de redução do saldo da Balança Comercial de pescado.

A partir de 2006 os déficits se tornaram crescentes, alcançando, em 2014, o montante de aproximadamente US\$ 1.258 milhões. Dentre os fatores que impulsionaram este resultado, estão: à imposição de barreiras no mercado internacional, principalmente, relativas ao camarão; a apreciação do câmbio; a mudança no padrão doméstico de consumo de proteínas, aumentando o consumo de pescado de 7,50 kg, em 1996, para 9,03 kg/ano, em 2009; e, mais recentemente, a crise financeira internacional (BRASIL, 2010).

O consumo per capita de pescados no Brasil é relativamente baixo quando comparado com outros tipos de carnes (bovinos, suínos e aves), ou em relação ao consumo de pescados em outros países no mundo. Dentre os fatores que interferem o baixo consumo está à sua demanda em que a mesma sofre variações quando relacionada ao hábito alimentar da população, as características de distribuição de renda, além da concorrência com outras fontes de proteínas animal e de alimentos (SANTOS, 2006).

Segundo dados do Boletim Estatístico da Pesca e Aquicultura (BRASIL, 2010), o consumo aparente per capita de pescado no país tem crescido desde 2005, sendo que, em 2010, atingiu 9,75 kg/hab./ano (Figura 10), com crescimento de $8 \%$ em relação ao ano anterior. Desse total, $66 \%$ do total consumido são produzidos no Brasil. 


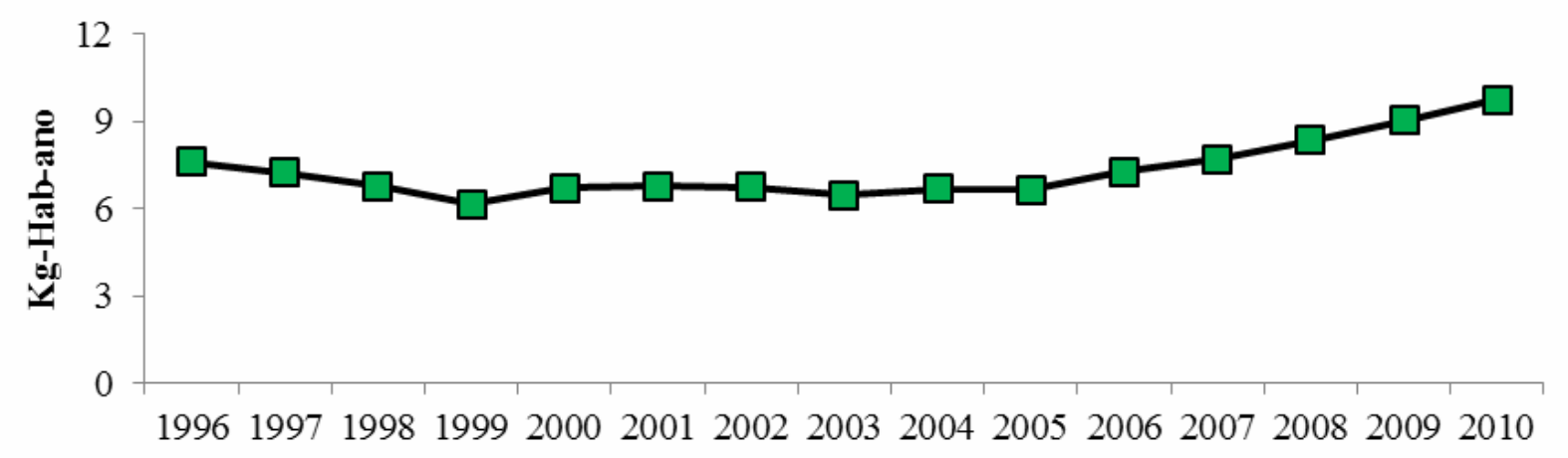

FIGURA 10. Consumo aparente per capita de pescado no Brasil de 1996-2010.

Fonte: BRASIL (2010).

O interesse pelo consumo de pescado surgiu devido às diversas qualidades nutricionais benéficas, cada vez mais estudadas que esta carne apresenta. Dentre tais qualidades estão 0 alto teor protéico, presença de vitamina A e D, íons importantes como cálcio e fósforo, ácidos graxos insaturados como ômega 3 e 6 , encontrados em algumas espécies e que estão relacionados à diminuição da incidência de doenças cardiovasculares (SANTOS, 2006).

Tratando-se do consumo per capita do pescado nas grandes regiões do Brasil, observa-se disparidade entre as mesmas. A região norte destaca-se, devido ao fato de que o peixe, em especial, é um elemento fundamental na alimentação da população e o consumo per capita é igual a 17,54 kg/hab./ano (Figura 11).

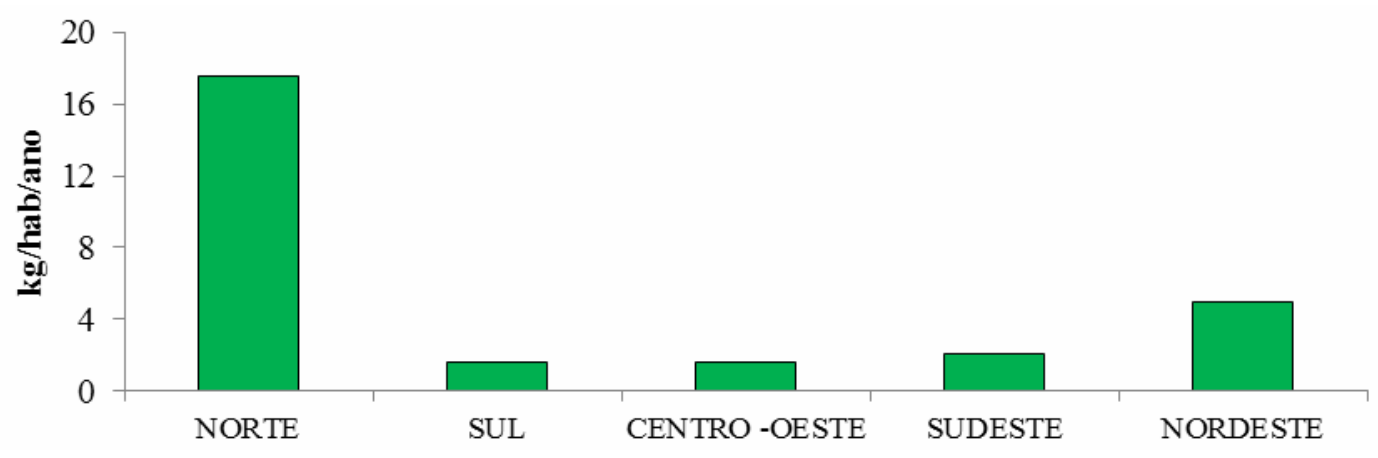

FIGURA 11. Consumo per capita de pescado nas grandes regiões do Brasil, 2008. Fonte: IBGE (2008).

Com relação ao consumo segundo os estados brasileiros, o do Amazonas aparece como maior consumidor, com $30 \mathrm{~kg} / \mathrm{hab}$./ano. Os demais estados da região norte como Pará, Acre e Amapá, também apresentam consumos significativos quando comparados ao restante do país na ordem de 18,70, 10,69 e 15,31 kg/hab./ano, respectivamente (Figura 12). Nos estados em que a pecuária bovina é forte, como por exemplo, o Rio Grande do Sul o consumo de pescado ainda é baixo (IBGE, 2008). 


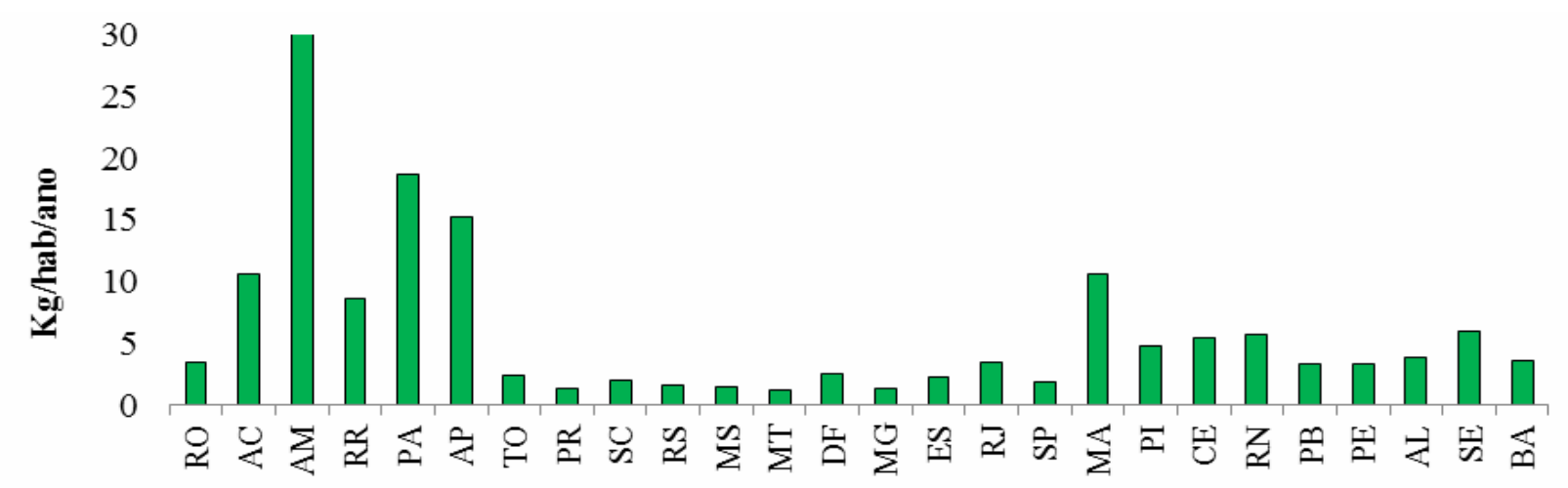

FIGURA 12. Consumo per capita de pescado por Unidade da Federação. Fonte: IBGE (2008).

A renda dos consumidores de pescado é uma variável determinante na demanda do produto. De acordo com os dados do IBGE (2008) o consumo per capita de pescado nas diferentes regiões do Brasil é mais alto na medida em que a renda se eleva (Figura 13). Porém, um comportamento distinto acontece na região Norte em que a renda não está afetando drasticamente no consumo, pois o mesmo na maioria dos casos continua alto. Fator este que pode ser explicado devido ao hábito alimentar da população.

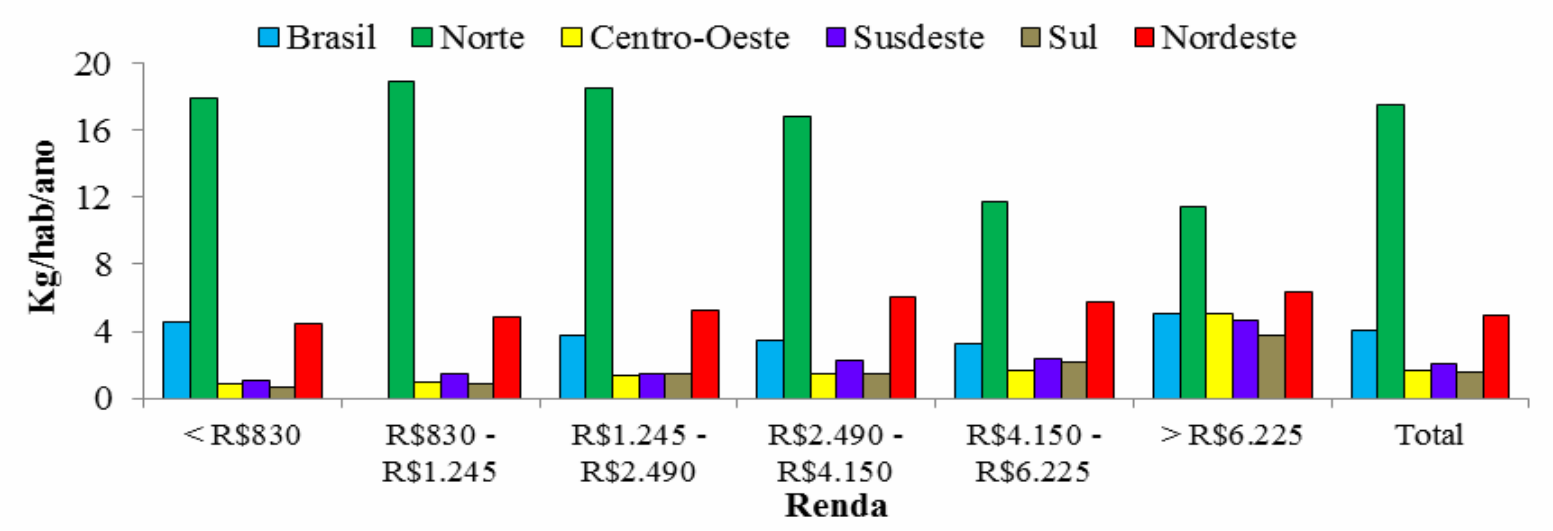

FIGURA 13. Consumo anual per capita de pescado por faixa de renda.

Fonte: IBGE (2008);

\section{Mercado regional}

A Amazônia dispõe de vários fatores que favorecem o desenvolvimento da aquicultura: clima, solo, água com qualidade e em abundância e, principalmente, a diversidade da fauna. Essa atividade é a alternativa mais viável para suprir a demanda crescente de proteína animal e diminuir a pressão da pesca predatória sobre os estoques naturais na região amazônica, o que tem motivado a implantação de novos investimentos no ramo (MELO et al., 2001). No entanto, a maior parcela da produção é da pesca extrativa, onde mesmo com intenso crescimento da atividade aquícola, a produção de captura ainda é muito superior (Figura 14). 


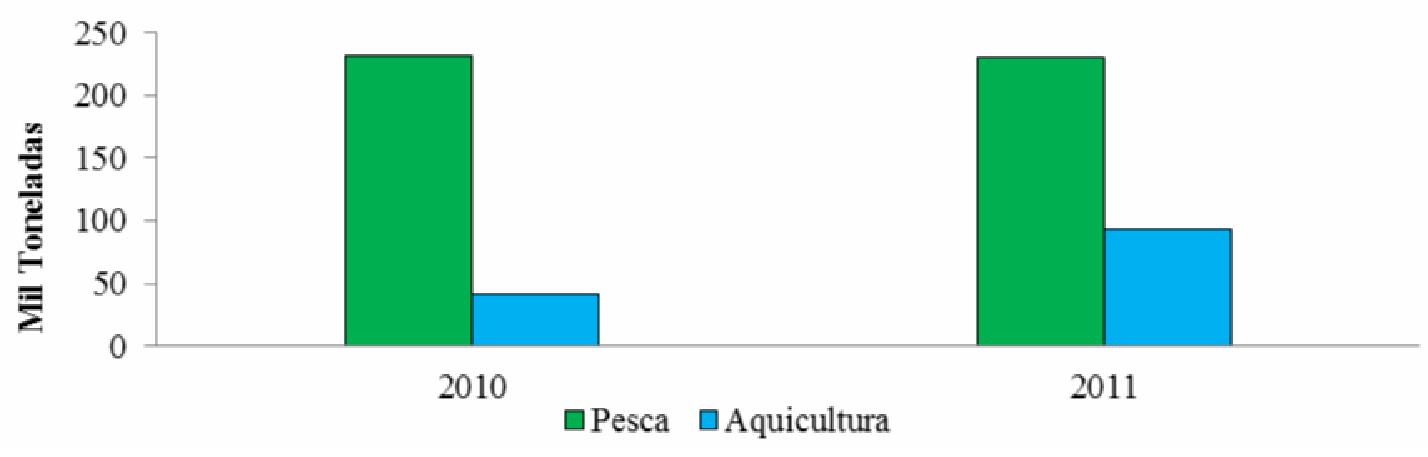

FIGURA 14. Produção da pesca e da aquicultura na região Norte, 2010 e 2011. Fonte: BRASIL (2011).

A produção de pescado em nível nacional alcançou seu ápice no ano de 2011, tendo a região Norte como grande principal produtora. No entanto é possível observar que a região Norte historicamente apresenta elevada participação da produção nacional (Figura 15).

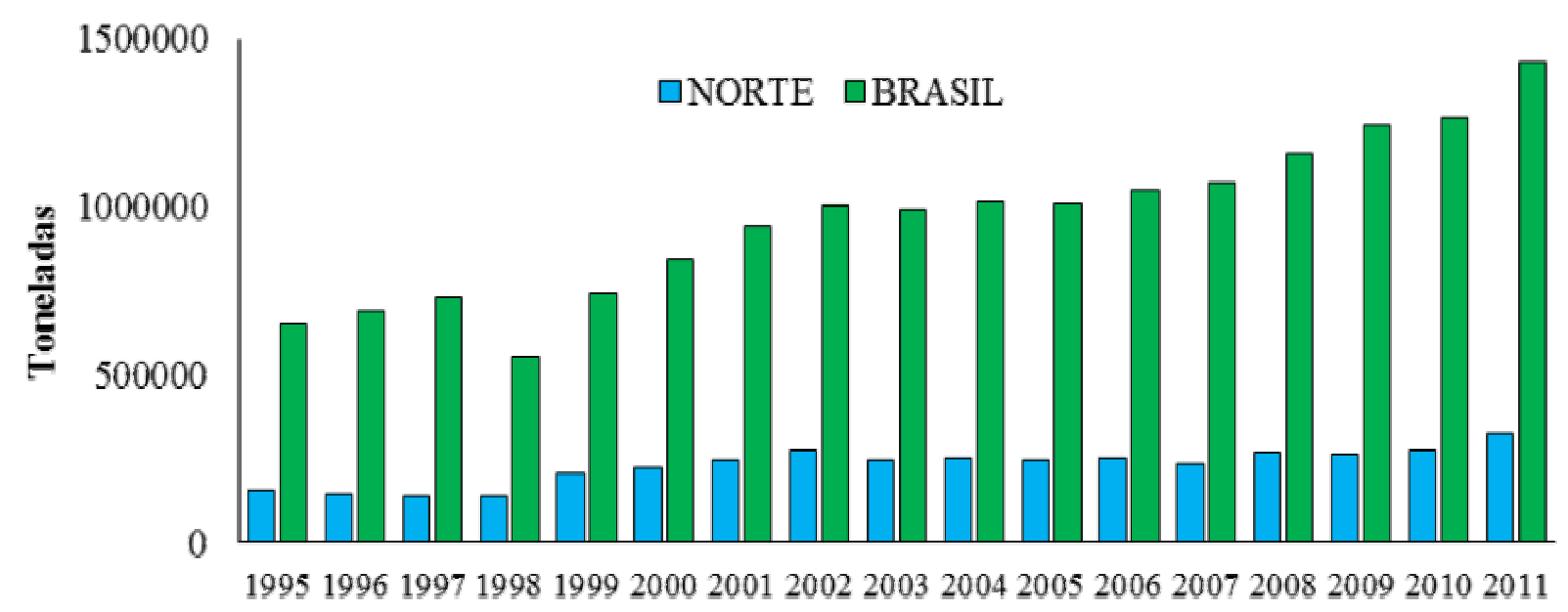

FIGURA 15. Produção de pescado Brasil e região Norte 1995-2011.

Fonte: BRASIL (2011).

Ao longo desse período pode-se constatar que houve uma ligeira estabilidade na produção de pescado na região Norte. Cabe ressaltar que a participação do Pará é bem expressiva, porém apresenta oscilações. Quando comparada com o Amazonas. Atualmente o Pará é responsável por $57,01 \%$ da produção da região Norte, enquanto o Amazonas ocupa o segundo lugar (Figura 16). 


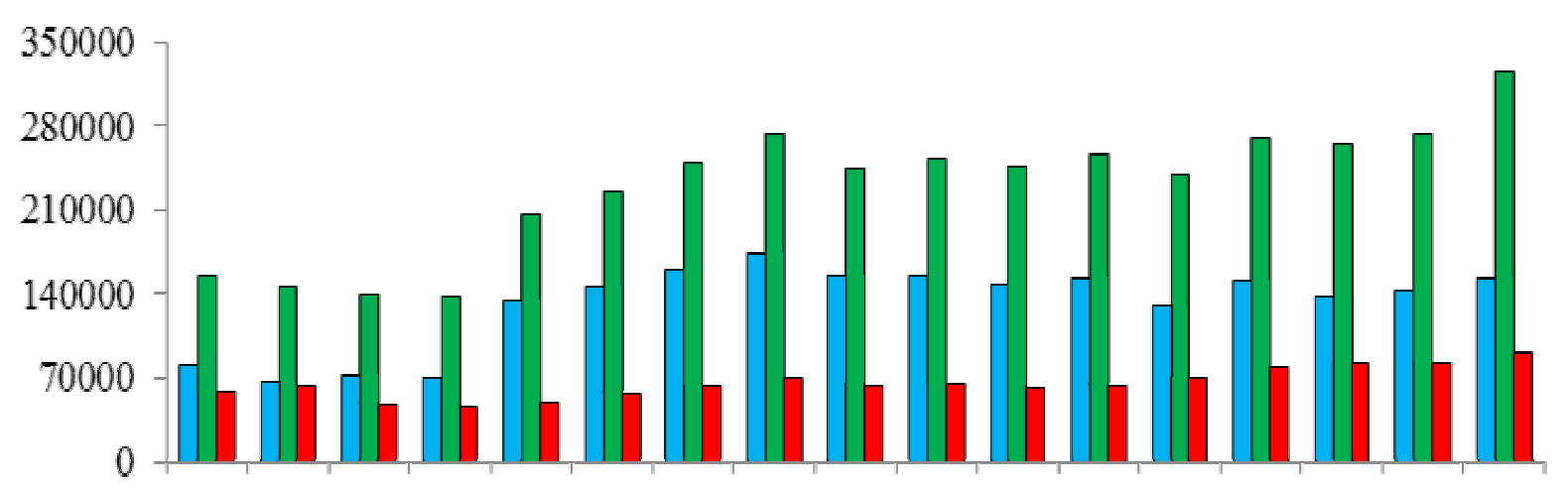

19951996199719981999200020012002200320042005200620072008200920102011

\section{口Pará $\square$ Norte $\square$ Amazonas}

FIGURA 16. Evolução da produção de pescado nos estados Pará, Amazonas e na região Norte.

Fonte: BRASIL (2011).

Com relação ao consumo de pescado na região norte, os dados do IBGE (2008) indicam que é superior à média nacional (Figura 17).

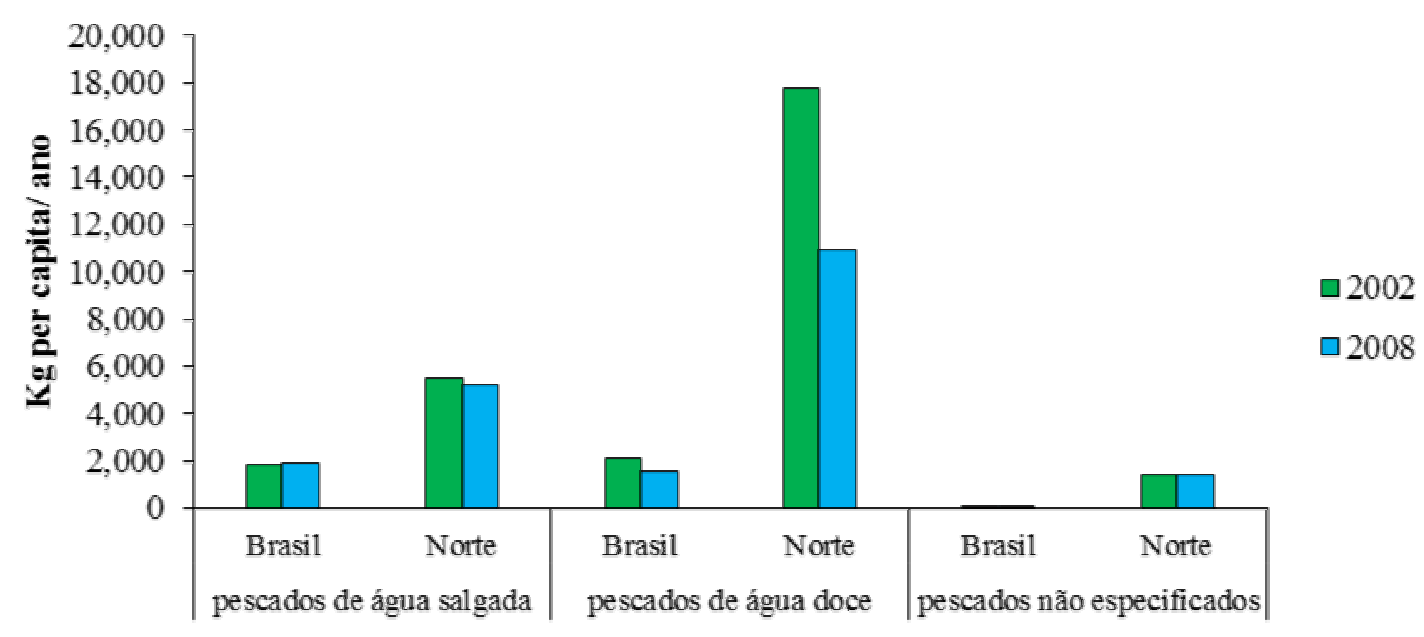

FIGURA 17. Consumo per capita de pescado segmentado nos grupos oficiais do IBGE.

Fonte: IBGE (2008).

A partir de mapas temáticos (Figura 18) é possível observar que o consumo é maior nas regiões Norte e Nordeste, apresentando um destaque para a região Norte. Analisando este aspecto, alguns pesquisadores analisam o setor pesqueiro observando que este é de ampla importância no contexto socioeconômico da região. Segundo a ONU (2010) essa atividade tende a aumentar os empregos no Brasil, desta forma, englobando a região Norte, uma vez que representa uma boa parcela no cenário pesqueiro nacional.

A aquisição domiciliar per capita especifica a quantidade em quilogramas a compra do produto em questão, quando se compara o consumo de pescado na região 
Norte constata-se que possui uma média de $17,544 \mathrm{~kg} / \mathrm{ano}$, sendo este valor acima do recomendado pela $\mathrm{FAO}$ que é de $12 \mathrm{~kg} / \mathrm{ano}$, diferenciando assim das demais regiões como se observa na figura 18 (MATIAS, 2014).
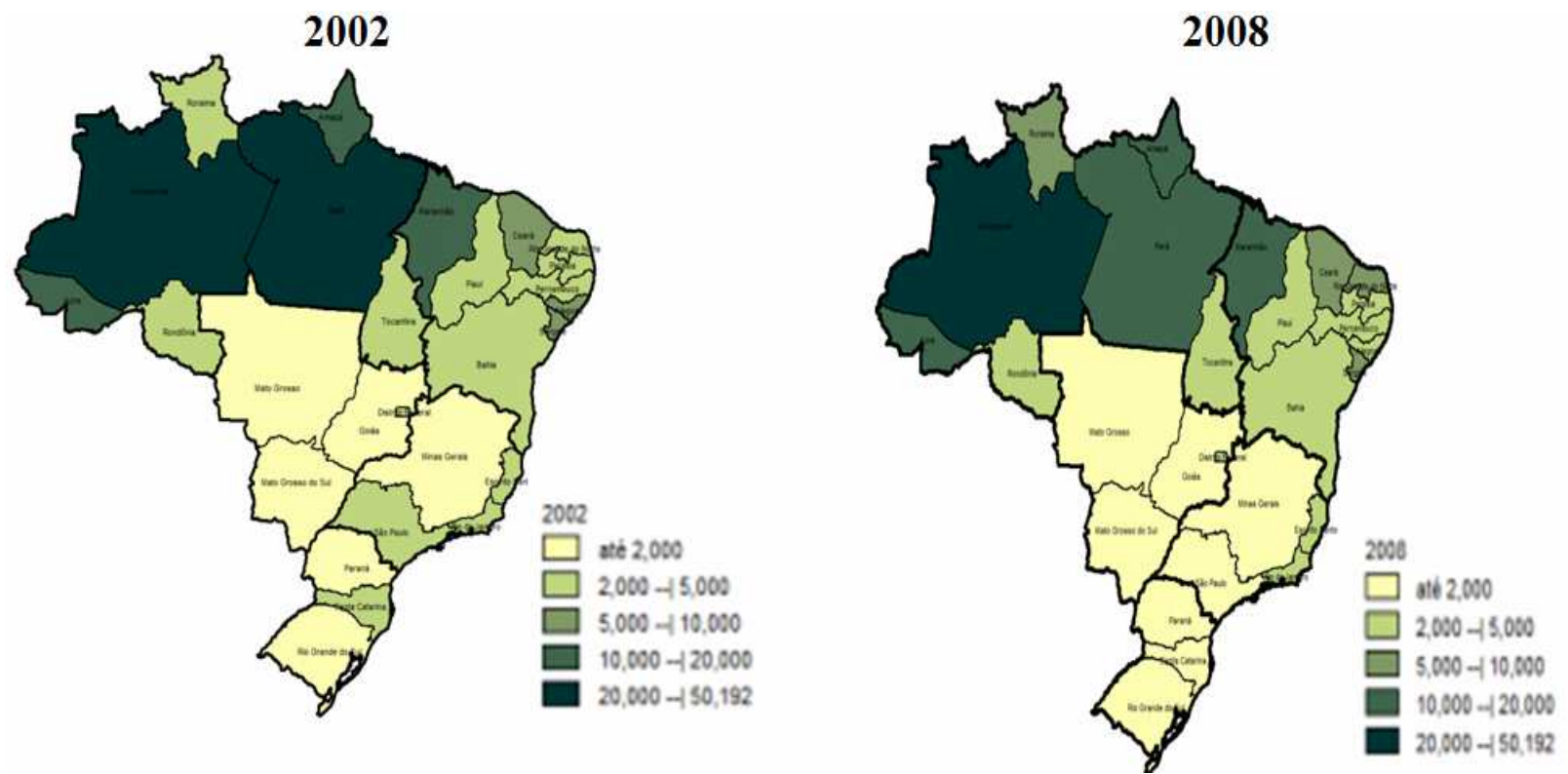

FIGURA 18. Aquisição domiciliar per capita anual de pescados (Kg per capita/ano)

Fonte: IBGE (2008).

brasileira nos anos de 2002 e 2008.

\section{CONCLUSÃO}

A produção mundial de pescado está concentrada no continente Asiático, com destaque para a China, maior produtor mundial. O Brasil, no entanto, acompanha a tendência do setor que é de crescimento da aquicultura. No Brasil, o consumo per capita de pescado ainda é baixo e não atende os padrões recomendados pela FAO. Mas, na região Norte, em função da disponibilidade do produto e do hábito da população está patamar superior à média nacional. A região Norte possui uma ampla contribuição na produção de pescado, onde se destacam os estados do Pará e Amazonas que ocupam o primeiro e segundo lugares na produção regional.

O Brasil e o estado do Pará exibem importante potencial para o desenvolvimento da aquicultura. $O$ desenvolvimento da aquicultura é fundamental para ampliar a oferta de pescado e atender o crescimento do mercado consumidor com qualidade e preços acessíveis, além de contribuir com a sustentabilidade da pesca extrativa a partir da redução da pressão sobre os recursos pesqueiros de águas marinhas e continentais.

\section{REFERÊNCIAS}

ABCC. Associação Brasileira de Criadores de Camarões. Balança comercial do pescado no Brasil. Disponível em:<http://abccam.com.br/site/ balanca-comercial-depescado-do-brasil-marco-de-2014. Acesso em: 24 abr. 2016.

BRASIL. Ministério do Desenvolvimento, Indústria e Comércio Exterior. Sistema 
Aliceweb. Disponível em:<http://www.desenvolvimento.gov.br>. Acesso em: 24 abr. 2016.

BRASIL. Ministério da Pesca e Aquicultura. Boletim estatístico da pesca e aquicultura, 2010. Disponível em: <http://www.mpa.gov.br>. Acesso em: 04 abr. de 2016.

BRASIL. Ministério da Pesca e Aquicultura. Boletim estatístico da pesca e aquicultura, 2011. Disponível em: http://www.mpa.gov.br/files/docs/Boletim_MPA_2011_pub.pdf>. Data de acesso em 04 de abril de 2016.

FAO. Food and Agriculture Organization of the United Nation. Fishery and Aquaculture Statistics. 2010. Disponível em:<http://www.fao.org>. Acesso em: 24 abr. 2016.

FAO. Food and Agriculture Organization of the United Nation. Statistical databases. 2014. Disponível em:<http://www.fao.org/documents/card/es/c/8af01c79-cb1f-42e5ae4a-d8531cf12794/>. Acesso em: 19 abr. 2016.

IBGE - Brazilian Institute of Geography and Statistics 2008. Sistema IBGE de Recuperação Automática - SIDRA. 2008. Disponível em: <http://www.sidra.ibge.gov.br/>. Acesso em: 24 abr. 2016.

ISAAC, V. J. Exploração e manejo dos recursos pesqueiros do litoral amazônico: um desafio para o futuro. Ciência e Cultura, São Paulo, v.58, n.3, p. 33-36, 2006.

ISAAC, V. J., MARTINS, A. S., HAIMOVICI, M., CASTELLO, J. P., ANDRIGUETTO, J. $M$. Síntese do estado de conhecimento sobre a pesca marinha e estuarina do Brasil. p. 11-40. 2006 .

LOPES, M.L.B, COSTA, P.A., SANTOS, J.S.B., CUNNHA, S.J.T., SANTOS, M.A.S., SANTANA, A.C. Mercado e Dinâmica Espacial da Cadeia Produtiva da Pesca e Aquicultura na Amazônia. Banco da Amazônia. 2010. (Estudos Setoriais, 7)

MATIAS, F. Aquicultura na América Latina e Caribe: situação atual, tendências e perspectivas, $2014 . \quad$ Disponível em: <http://fenacam.com.br/pdf/fenacam2014/aquicultura/6-aquicultura-na-america-latinasituacao-atual-e-perspectivas-_felipe-matias.pdf >. Acesso em: 28 abr. 2016.

MELO, L.A.S., IZIEL, A.C.U., RODRIGUES, F.M. Piscicultura: alternativa sustentável para o agronegócio da Amazônia. Belém: Embrapa Amazônia Ocidental. 2001.

ONU. Organização das Nações Unidas. Segundo especialistas, pesca pode aumentar no Brasil e gerar mais empregos. Disponível em:<https://nacoesunidas.org/fao-segundo-especialistas-pesca-pode-aumentar-nobrasil-e-gerar-mais-empregos/>. Acesso em: 24 abr. 2016.

ENCICLOPÉDIA BIOSFERA, Centro Científico Conhecer - Goiânia, v.14 n.26; p. 195 2017 
SANTOS, C. A. M. L. A qualidade do pescado e a segurança dos alimentos. In: Simpósio de Controle do Pescado, 2, 2006. São Paulo: Instituto da Pesca. 2006. 6p.

SUGUIO, K., TESSLER, M. G. Planícies de cordões litorâneos quaternários do Brasil: origem e nomenclatura. In: L. D. LACERDA et al. (Org). Restingas: origem, estrutura e processos. Niterói: 15-25. CEUFF, Niterói, 1984. 